\title{
Design and Development of a Compact Rat-Race Coupler
}

\author{
Sukhdas Ahirwar $^{1}$, D. Ramakrishna ${ }^{2}$,V.M. Pandharipande ${ }^{3}$ \\ ${ }^{1}$ Defence Electronics Research Laboratory (DLRL), Hyderabad, Pin Code-500005, Telangana, India. \\ ${ }^{2-3}$ Centre for Excellence in Microwave Engineering (CEME), Dept. of ECE, University college of Engineering, \\ Osmania University, Hyderabad, Pin Code-500007, Telangana, India \\ *corresponding author, E-mail: sdahirwar@rediffmail.com
}

\begin{abstract}
In this paper, design and development of compact Rat- Race coupler is presented. The device is designed with commercial available semi rigid coaxial cable. The semi rigid coaxial is modified for desired impedance required for design of Rat- race hybrid coupler. The physical structure of the coupler is in rectangular form instead of the conventional ring form. With this structure all the ports are available in line on the same side. This eases the integration of the device with other modules or devices in the system. The total area occupied the coupler is reduced drastically by meandering the transmission line. The shielded transmission line provides lesser undesired coupling to other ports and has less line radiation loss. Design, implementation and measured results are presented.
\end{abstract}

\section{Introduction}

With rapid advancement in wireless communication systems and other microwave systems, these systems are being miniaturized. This leads to the compact and handheld devices and systems. This compactness is dependent on the compactness and miniaturization of components and devices. The couplers are basically power dividers/ combiners with equal or unequal power division and with or without phase shift. Branch line couplers [1, 2], power dividers [3-7] and hybrid ring couplers $[8,9]$ are the some of the power dividing/ combining devices. The rat-race coupler is one of basic building blocks used in RF and microwave circuits. The rat-race coupler is transmission line based device in which output appearing at a particular port depends on the phase of the signals arriving at that port following different paths. Accordingly this can be designed and implemented in wave guide as magic Tee. In micro strip line, strip line and co-planar wave guide, it is implemented as $3 \mathrm{~dB}$ hybrid coupler. In these designs, the implementation is easier where the characteristics impedance of the line can be changed by changing the widths of the corresponding lines. The rat-race coupler design based on the micro strip line is very popular. In micro strip line configuration, other phasing techniques are used to reduce the size of the coupler [11-13]. The various coupler designs [14] are compared for their performances with respect to form factors of these couplers.
In micro strip design, the ground plane is an integral part of the system and hence less portability. For realization of these couplers we require to use a ring of one and half wave length circumference and hence it occupies more area. More over the ports of the coupler are located along the periphery and they cannot be put in line. For compactness if the micro strip line is meandered then the line loss increases.

In this paper, a coupler in coaxial transmission line in new type of configuration is presented overcoming the problems associated with the conventional ring micro strip couplers. With this implementation the overall occupying area of the coupler is reduced by 66.8 percent.

\section{Theory}

The Rat-race coupler is a 4-port device [10] which can be used as a power divider or power combiner. The phase of output for some port combination may be $0^{\circ}$ or $180^{\circ}$ depending upon the input- output combinations. The schematic and symbol of $180 \mathrm{deg}$. hybrid is shown in Fig. $1(a, b)$. Depending upon the input- output combinations the hybrid can be used as -
(a) In -phase power splitter
(b) Out-of phase power splitter and
(c) Power combiner

Port $1 \quad \lambda / 4 \quad$ Port 3

$(\Sigma)$

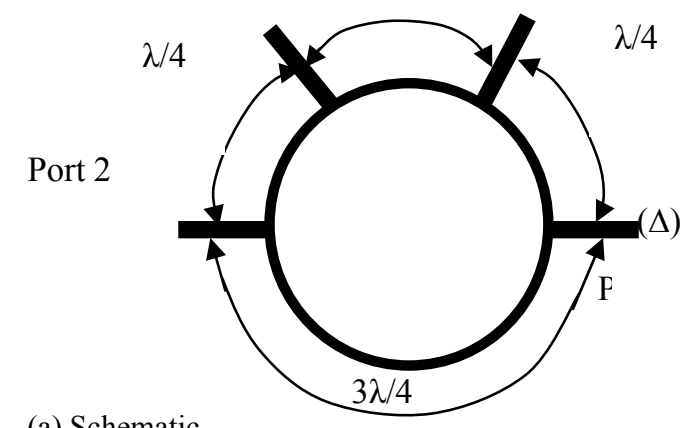

(a) Schematic 
$(\Sigma)$

$(\Delta)$

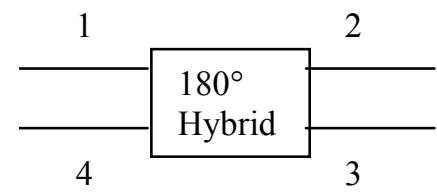

(b)

Fig 1: Representation of Coupler

(a) Schematic of Rat-Race Coupler

(b) Symbol of Rat-Race Coupler

When port 1 is used as an input port this signal is equally divided in two pats travelling clockwise and anti clockwise respectively with respect to port 1 . The distance travelled by signal travelling in clockwise direction from portl to port 2 is $5 \lambda / 4$ and the distance travelled by other half signal following anti clockwise direction is $\lambda / 4$. Path difference between these two signals is $\lambda$. Outputs at this port are in phase. Similarly the outputs will be in phase at port 3 by similar reason. The signals travelling to port 4 have the path difference of $\lambda / 2$ and due to this $180^{\circ}$ phase difference no output appears at this port and it is isolated port for the signal input at port 1 .If power is applied at port 4 , it divides in two out of phase equal signals between ports 2 and 3, port 1 being isolated port. When the device is used as a power combiner, the two inputs are applied at ports 2 and 3 the output appears at port 1 as the summation of these two inputs and difference will appear at port 4 . Due to this behavior of the coupler port 1 is called as the sum port while port 4 as difference port.

Scattering matrix for $180^{\circ}$ hybrid ring coupler is given by [10]

$[\mathrm{S}]=(-\mathrm{j} / \sqrt{ } 2)\left[\begin{array}{cccc}0 & 1 & 1 & 0 \\ 1 & 0 & 0 & -1 \\ 1 & 0 & 0 & 1 \\ 0 & -1 & 1 & 0\end{array}\right]$

This matrix shows the various input output combinations. Elements of this matrix can be obtained using the even-odd mode analysis technique [15]. For input at port 1 , if $B_{1}, B_{2}$, $\mathrm{B}_{3}$ and $\mathrm{B}_{4}$ are the amplitudes of scattered waves from the coupler then following results are obtained:

$B_{1}=0, B_{2}=-j / \sqrt{ } 2, B_{3}=-j / \sqrt{ } 2$ and $B_{4}=0$. These results show that input port (port1) is matched port, port 4 is isolated port and the signal is divided in same phase between port 2 and 3. Above results are the first row and first column elements of above scattering matrix. Similarly the other elements can be obtained. For $50 \Omega$ port impedance, the characteristics impedance of the ring must be $70.7 \Omega$ to satisfy the working principle of the coupler.

\section{Design and Realization}

The required characteristics impedance of the line for the coupler design is $Z_{0} \sqrt{2}$, where $Z_{0}$ is the characteristics impedance of port. In this condition all the ports will be matched ports with respect to the coupler line. In case of micro strip lines, the line of any desired characteristics impedance can be designed easily. In case of coaxial it is not so i.e. this cannot be designed and developed like micro strip line due to its construction complexity. To solve this problem, a commercially available semi rigid coaxial cable is used. A $0.141 "(3.58 \mathrm{~mm})$ coaxial is used [16] for this purpose. The characteristics impedance of the coaxial transmission is given by

$$
\mathrm{Z}_{0}=\left(138 / \sqrt{ } \varepsilon_{\mathrm{r}}\right) \log _{10}(\mathrm{D} / \mathrm{d}) \quad \Omega
$$

Where $\mathrm{D}$ is the inner diameter of outer conductor and $\mathrm{d}$ is outer diameter of inner conductor respectively. $\varepsilon_{\mathrm{r}}$ is the permittivity of the dielectric material separating the inner and outer conductors of the coaxial cable. The PTFE is the dielectric material of the cable having $\varepsilon_{\mathrm{r}}=2.1$. The other dimensions of this cable are:

$$
\begin{aligned}
& \mathrm{D}=2.98 \mathrm{~mm} \\
& \mathrm{~d}=0.91 \mathrm{~mm}
\end{aligned}
$$

using equation (2), impedance of this line is $50 \Omega$. For coupler design, the required the line impedance is $Z_{0} \sqrt{ } 2=$ $50 \mathrm{x} \sqrt{2}=70.7 \Omega$. For this the center conductor of the semi rigid coaxial is replaced by commercially available copper wire of diameter $0.57 \mathrm{~mm}$ (AWG-23). With this configuration, the calculated impedance of the line is $68.4 \Omega$. This can be approximated as the required impedance and this serves our purpose. The line length chosen for design is 540 $\mathrm{mm}$. The velocity factor for this line is 0.69 due to dielectric constant of 2.1. The electrical length of the line is-

$$
\mathrm{L}=1.5 \lambda=540+540 \times 0.69=912.6 \mathrm{~mm} .
$$

This gives $\lambda=608.4 \mathrm{~mm}$ and hence the frequency corresponding to this wave length is $493.1 \mathrm{MHz}$. This is the operating frequency of the coupler. For size reduction, the line length is meandered in such a manner that after joining the ends of the line the ports located at $\lambda / 4$ intervals must come in a line. For this the line folded and meandered as shown in Fig. 2. First three $\lambda / 4$ sections are meandered and remaining line is the combination of meandered part and rectangular folding. Every vertical and horizontal sections of the meandered structure are $25 \mathrm{~mm}$ and $20 \mathrm{~mm}$ respectively. Other dimensional details are shown in Fig. 2. The line is folded maintaining the minimum bending radius of the line. The isometric view of the coupler is shown is Fig. 3. For feeding at the ports another commercially available semi rigid coaxial of $0.86 "(2.18 \mathrm{~mm})$ is used. At port positions holes are drilled in 0.141 " coaxial cable up to axis of the cable. This is to solder the center conductor of the feed cable to the 0.141 " cable. The outer conductors of these cables are soldered together at the Tee junctions of the cables. The 
photograph of the designed and realized rat-race coupler is shown in Fig. 4.

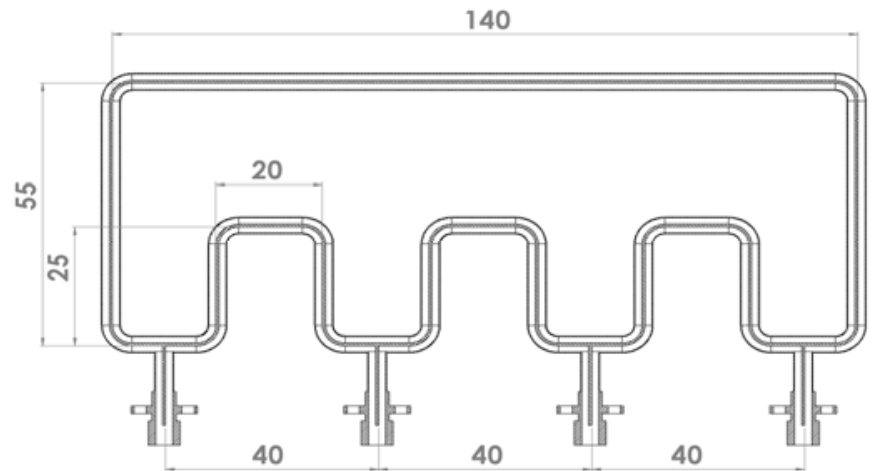

Fig. 2: Sectional view of Rat-Race coupler

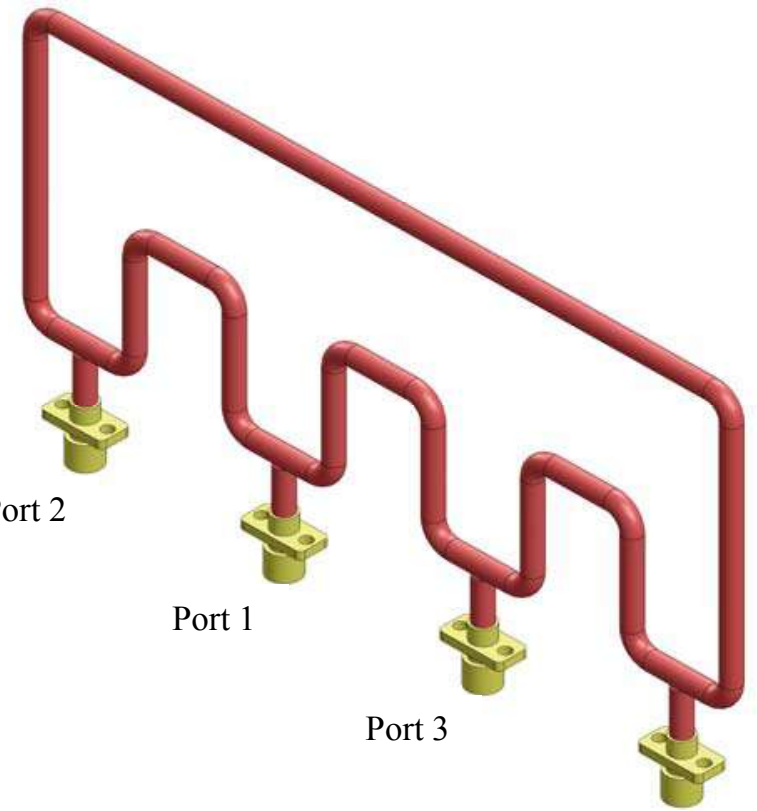

Port 4

Fig.3: Isometric view of Rat-Race coupler

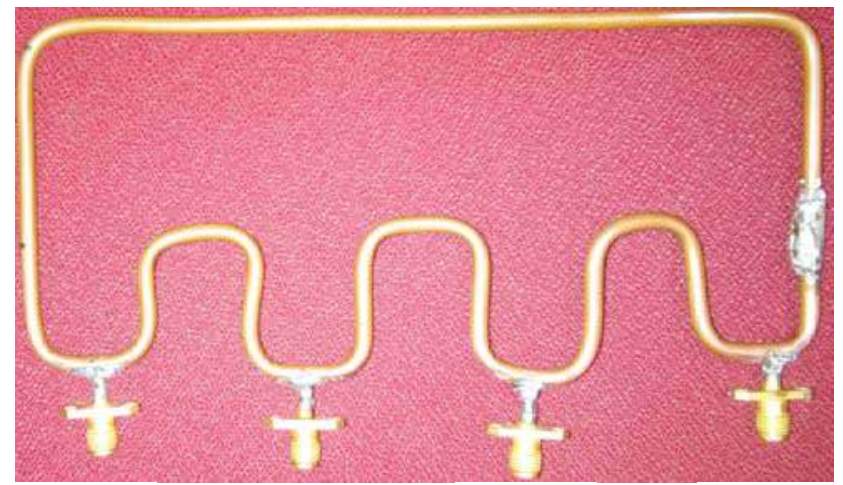

Port 2

Port 1

Port 3

Port 4

Fig. 4: Photograph of Rat-Race coupler
In order to compare the performance of the coaxial line coupler, the micro strip transmission line coupler in its conventional ring form and in proposed compact forms are designed and simulated in ADS circuit simulating tool. For this height of the substrate is taken as the thickness of dielectric of coaxial cable. The schematics and layouts for these couplers are shown in Fig. 5(a, b) and 6(a, b) respectively. The coaxial line coupler could not be simulated due to lack of coax curve modeling in the GUI of the simulation software.
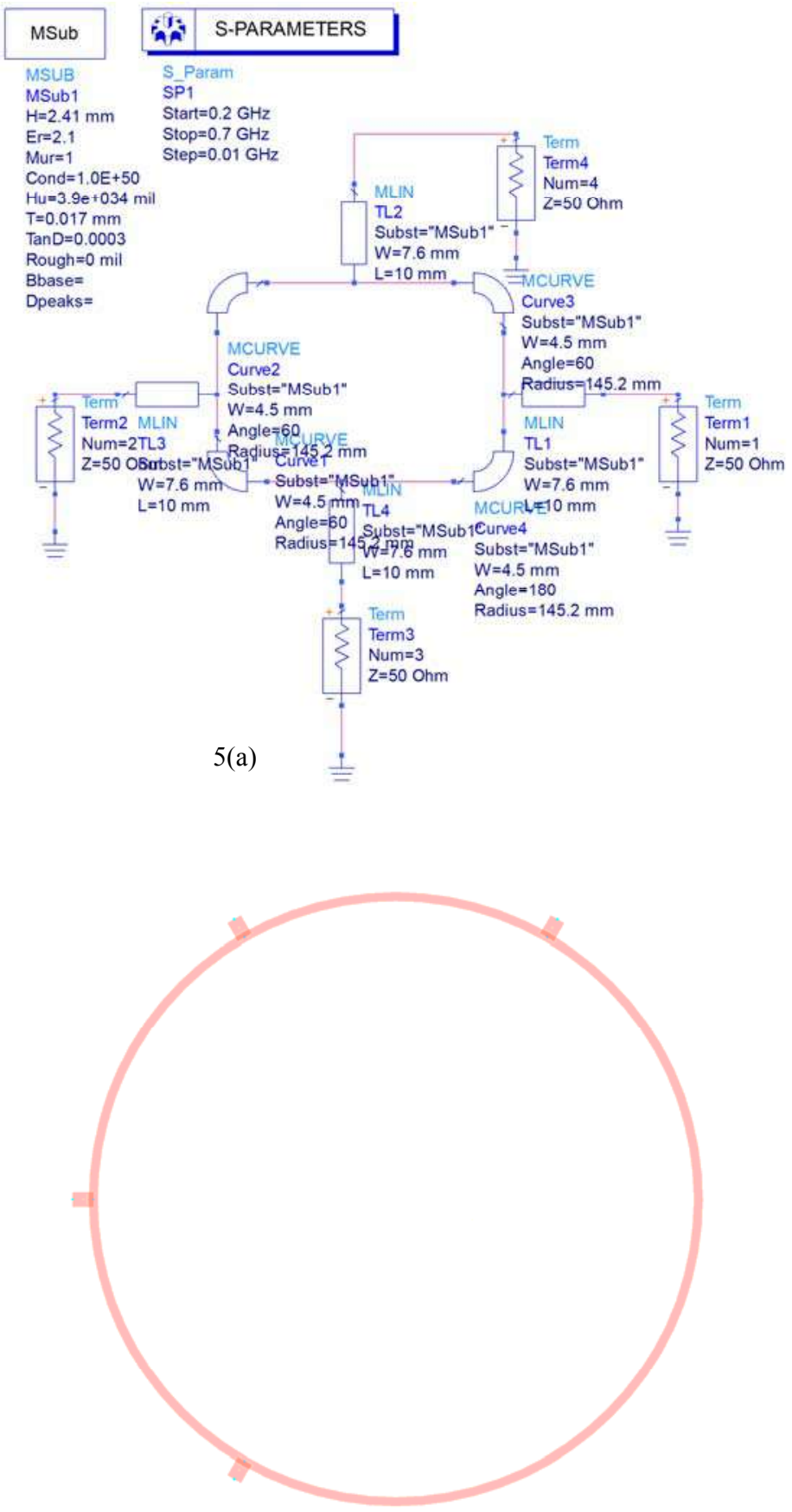

$5(b)$

Fig. 5: Simulation model of micro strip ring Rat-Race coupler (a) Schematic (b) Layout 


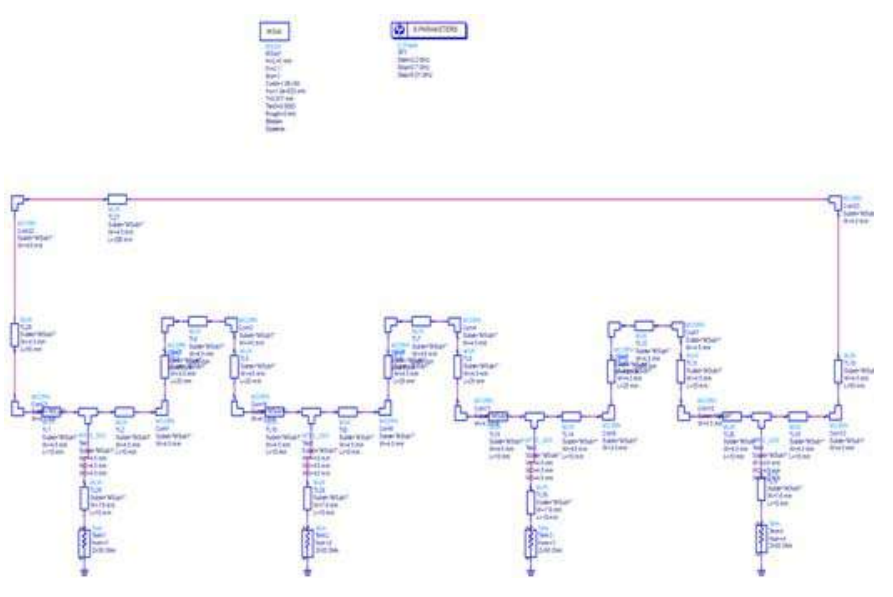

6(a)

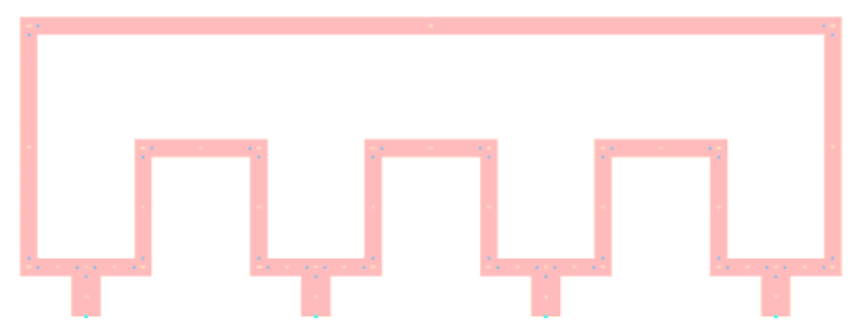

6(b)

Fig. 6: Simulation model of micro strip compact Rat-Race coupler (a) Schematic (b) Layout

\section{Results and Discussion}

A well designed coupler should have good return loss at input port, high isolation at isolated port and $3 \mathrm{~dB}$ power division at output ports. At output ports, practically there will be some insertion loss of the transmission line and hence output at these ports will be always less than $3 \mathrm{~dB}$. Also there will be power difference at output ports, this is defined in terms of amplitude balance. Similarly the phase difference between these two ports is known as phase balance. Using port 1 as an input port the magnitude of $S_{11}$ will show the return loss, $S_{21}$ and $S_{31}$ are the $3 \mathrm{~dB}$ power division and $\mathrm{S}_{41}$ will show the isolation of the coupler.

The designed and realized compact Rat-race coupler was evaluated for its S-parameters using M/s Agilent E5071C Network Analyzer. Measured S-parameters results are shown in Fig. 7(a-d). As can be seen from Fig. 7(a), the achieved return loss (mag. $S_{11}$ ) is $\geq 20 \mathrm{~dB}$ over the working frequency range of the coupler. The maximum return loss is $39.8 \mathrm{~dB}$. This shows that all the ports are well impedance matched. Fig. 7(b) shows the measured port isolation $\left(\mathrm{S}_{41}\right)$. It is evident from the plot that the port isolation is more than $20 \mathrm{~dB}$ over the band. The maximum value is reaching to $50 \mathrm{~dB}$. The $3 \mathrm{~dB}$ power divisions $\left(\mathrm{S}_{21}\right.$ and $\left.\mathrm{S}_{31}\right)$ are shown in Fig.7(c) and Fig. 7(d) respectively. The 3dB coupling band width for port $2\left(\mathrm{~S}_{21}\right)$ is $487.4 \mathrm{MHz}$ to $840.2 \mathrm{MHz}$ with maximum insertion loss of $0.6 \mathrm{~dB}$. For port 3 the above band width is reduced to $487.4 \mathrm{MHz}$ to $641.6 \mathrm{MHz}$ with maximum insertion loss of $1 \mathrm{~dB}$. This bandwidth can be considered as the actual operational bandwidth. The achieved amplitude balance is $\pm 0.25 \mathrm{~dB}$ between ports 2 and 3 .

The measured phase difference between two in phase output ports is shown in Fig. 8. As evident from this measured phase difference plot, the measured phase balance is within \pm $2.2^{\circ}$ over the frequency band of interest. The bandwidth for these specifications is $27 \%$.

The performance comparison of the three designs is shown in table 1.

Table 1: Performance comparison of three types of coupler designs

\begin{tabular}{|l|l|l|l|l|l|}
\hline$\underset{\text { Parameter }}{\longrightarrow}$ & $\begin{array}{l}\text { Freq. } \\
\text { band of } \\
\text { operation } \\
\text { Coupler } \\
\text { type }\end{array}$ & $\begin{array}{l}\text { Center } \\
\text { frequency } \\
(\mathrm{MHz})\end{array}$ & $\begin{array}{l}\text { \% } \\
\text { band }\end{array}$ & $\begin{array}{l}\text { Max. } \\
\text { weturn } \\
\text { loss } \\
(\mathrm{dB})\end{array}$ & $\begin{array}{l}\text { Port } \\
\text { isolation } \\
(\mathrm{dB})\end{array}$ \\
\hline $\begin{array}{l}\text { Micro } \\
\text { strip line } \\
\text { Ring }\end{array}$ & $340-400$ & 370 & 16 & 36 & 53 \\
\hline $\begin{array}{l}\text { Micro } \\
\text { strip line } \\
\text { Compact }\end{array}$ & $440-550$ & 480 & 23 & 59.5 & 59.5 \\
\hline Coaxial & $487-641$ & 558 & 27 & 40 & 50 \\
\hline
\end{tabular}

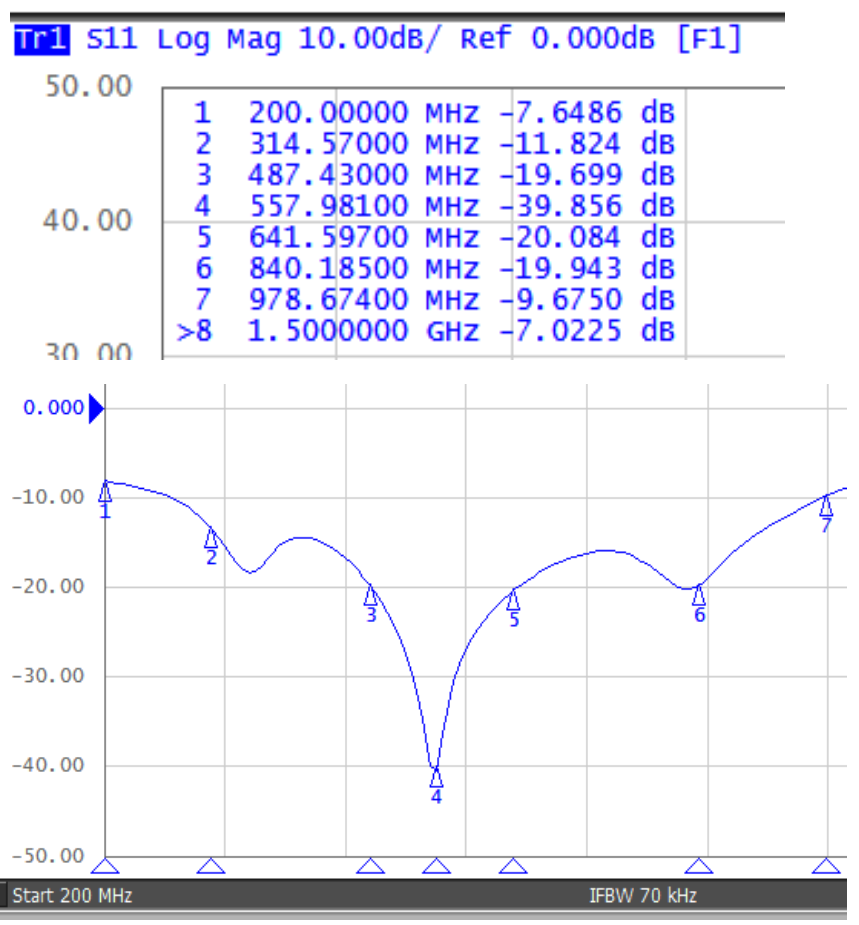

7(a) 
From this comparison it can be seen that the operational bandwidth for compact designs is better for similar electrical characteristics. The S- parameter plots for micro strip ring and compact coupler designs are shown in Fig. 9 and Fig. 10 respectively.

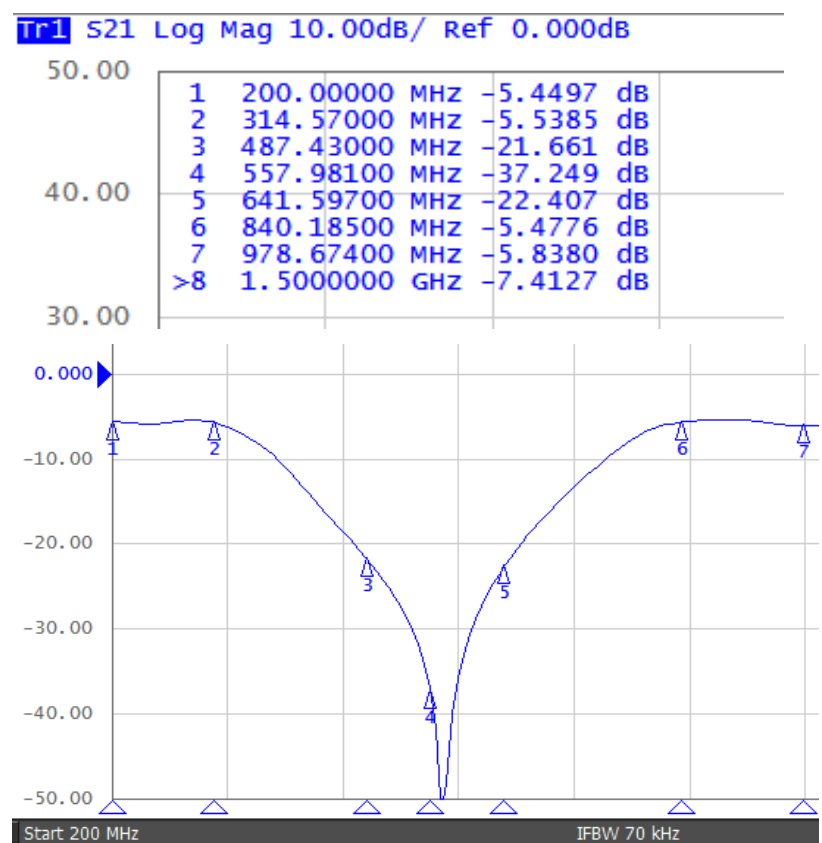

7(b)

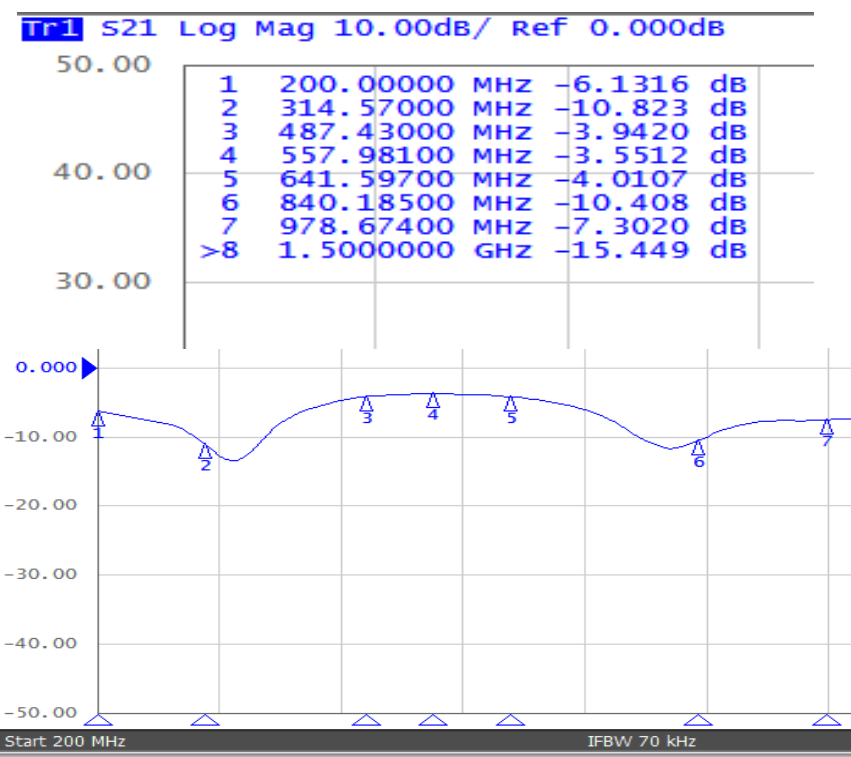

7(d)

Fig. 7: Measured S- Parameters of the proposed $3 \mathrm{~dB}$ Coupler (a) Return Loss

(b) Port isolation $\left(\mathrm{S}_{41}\right)$

(c) Coupled Power $(3 \mathrm{~dB})$ at port $2\left(\mathrm{~S}_{21}\right)$

(d) Coupled Power $(3 \mathrm{~dB})$ at port $3\left(\mathrm{~S}_{31}\right)$

\section{W5071C Network Analyzer}

1 Active Ch/Trace 2 Response 3 Stimulus 4 Mkr/Analysis 5 Instr State Tr'1 521 Phase $90.00^{\circ} /$ Ref $0.000^{\circ}$ [D/M]

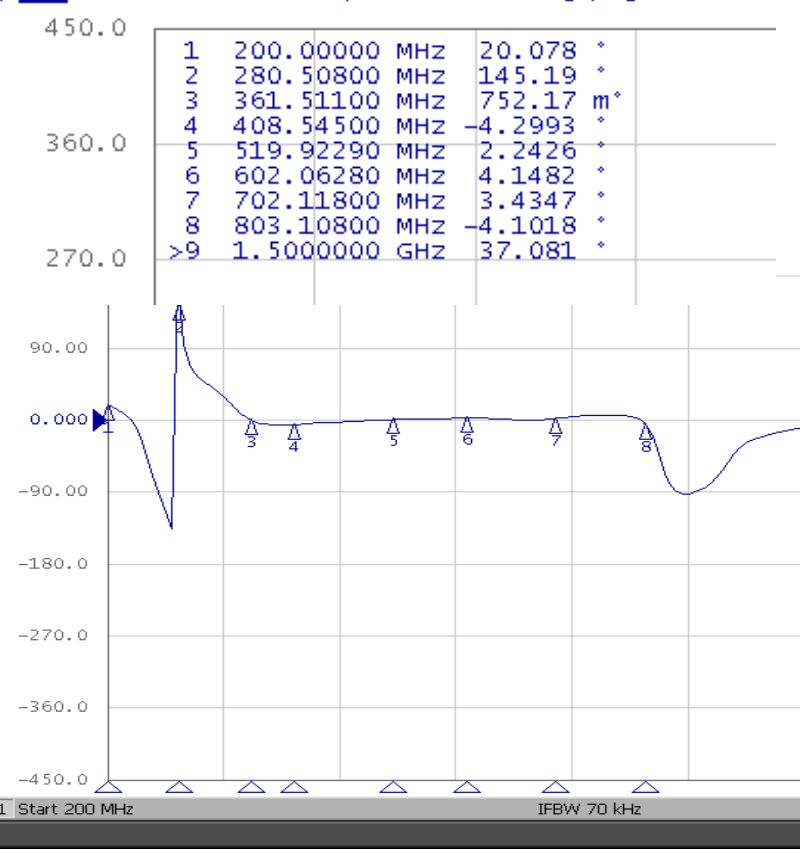

Fig.8: Measured phase balance of Rat-Race coupler

$7(\mathrm{c})$ 


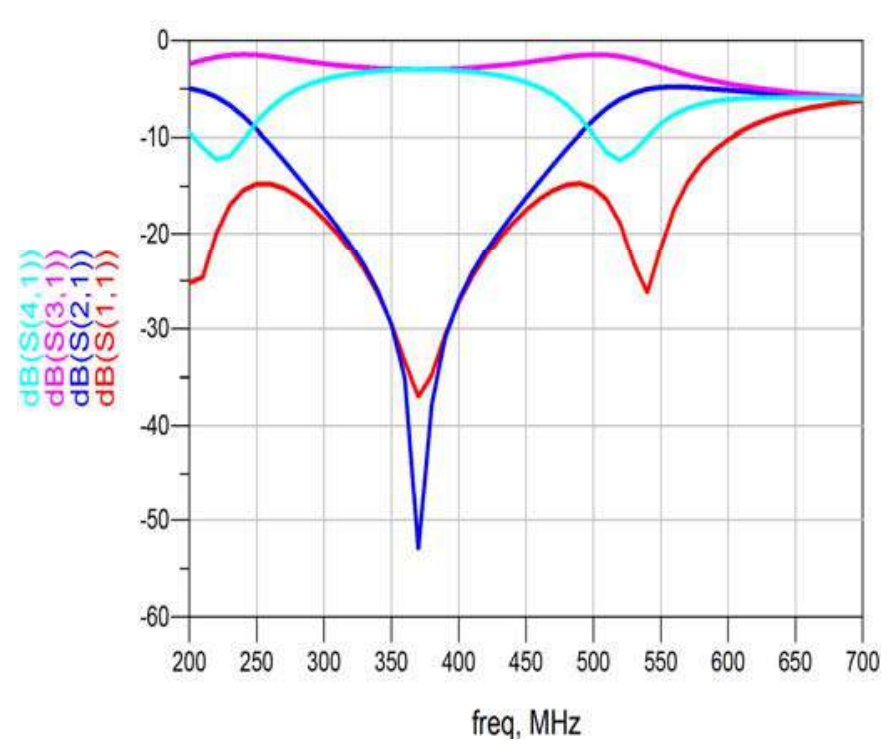

Fig .9: Simulated S- parameters of micro strip Ring Rat-Race coupler

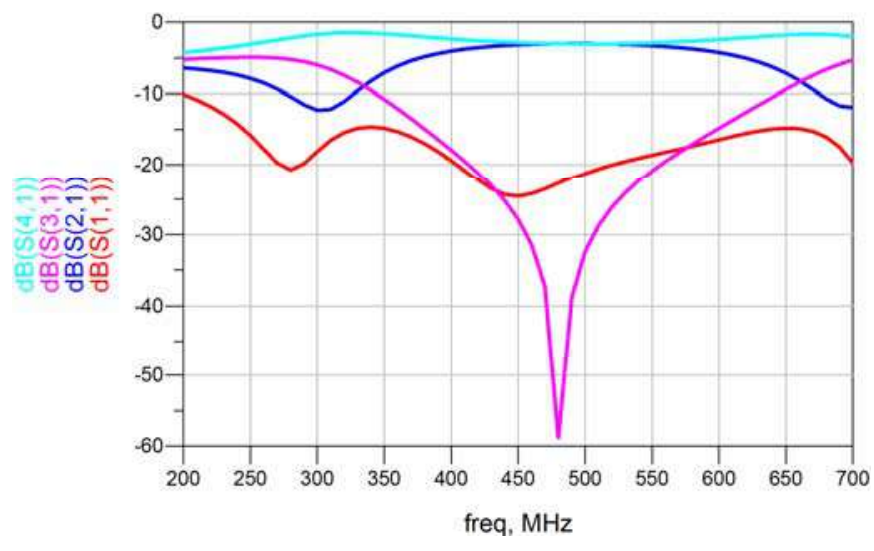

Fig .10: Simulated S- parameters of micro strip Compact Rat-Race coupler

\section{Conclusion}

A new type of Rat-Race coupler is designed and developed. A commercially available semi rigid coaxial cable is modified to achieve the required impedance for coupler design. The shielding effectiveness of the semi rigid coaxial is very high compared to micro strip line and hence the proposed coupler can be used with minimum interference to other devices and systems. This is also suitable for portable applications. The designed coupler has all the ports one side and this facilitates easy integration with other sub systems. Size of the coupler in this design is reduced by $66.8 \%$ compared to conventional ring type designs. An operational bandwidth of the coupler is $27 \%$ which is expected for this type of $\lambda$ dependent designs. It is light weight as it does not require any ground plane.

\section{Acknowledgements}

Authors would like to Dr A.K. Singh, OS and Director, DLRL and Shri M. Balachary, OS \& Associate Director, DLRL, for constant encouragement and support for carrying out the research work.

\section{References}

[1] K.V. Phani Kumar, Rusan Kumar Barik, SS Karthikeyan, "A novel two section branch line coupler employing different transmission Line techniques", $A E U$ International Journal of Electronics and Communications, Vol.70, Issue 5, May 2016, pp.738-742.

[2] Mehrdad Naderi, Hamed Abbasi, "Design of Compact Microstrip Branch Line coupler using Semi- circular rectangular resonators with wide range suppressed harmonics", AEU- International Journal of Electronics and Communications, Vol.84, Feb. 2018, pp.171-176.

[3] Mahdi-Moradian, "Wideband Slot Coupled Power dividers", AEU-International Journal of Electronics and Communications, Vol.82, Dec. 2017, pp.327-333.

[4] Hamed Shahi, Hossein Shamsi, "Compact Wideband Gysel Power dividers with harmonic Suppression and arbitrary power division Ratios", AEU- International Journal of Electronics and Communications, Vol.79,Sep. 2017, pp.16-25.

[5] Xiao Yang, XuChun Zhang, ZhenHeng Liao, “A Novel Planar Four-way Power divider with large dividing ratio", AEU- International Journal of Electronics and Communications, Vol.85, Feb.2018, pp. 1-6.

[6] Ashraf S. Mohra and Majeed A. Alkanhal, " Dual Band Wilkinson Power Dividers Using T-Sections" Journal of Microwaves, Optoelectronics and Electromagnetic Applications, Vol. 7, No. 2, December 2008, pp-83-90.

[7] Zhen Yang, Weiguo Liu, "A Balanced-to-Single-Ended Wilkinson Power Divider “,Journal of Microwaves, Optoelectronics and Electromagnetic Applications, Vol. 16, No. 3, September 2017, pp-777-784.

[8] Suwan Janin, Keattisak Sripimanwat, Chuwong Phong Charoenpanich, Monai Krairiksh, "A hybrid Ring Coupler Quasi-optical Antenna Mixer”, AEUInternational Journal of Electronics and Communications, Vol.63, Issue 1,17 Jan. 2009, pp.36-45.

[9] Mohammad Beigizadeh, Rasoul Dehghani, Abdolreza Nabavi, "Analysis and design of lumped element Hybrid International Journal of Electronics and Communications, Coupler using limited quality factor Components", AEU Vol.82, Dec. 2017, pp.312-320.

[10] David M. Pozer, "Microwave engineering", John Willey and Sons Inc. Publication, third ed., 2005.

[11] Lin-Zong, Jan-Dong,Binshu Wu, Jhih-Min Li, "Hybrid type Rat-Race Coupler designs", APEMC-2015.

[12] Y-C Chiou, J-T Kuo and C-H Chan, "New miniaturized dual band rat-race coupler with microwave C-sections", IEEE MTT-S Int. Microwave Sympo. Dig. 2009, pp.701-704. 
[13] Iulia Andreea Mocanu, Teodor Petrescu, “ Novel dual band hybrid Rat-Race with CRLH and D-CRLH transmission Lines", Proc. of the Asia Pacific Microwave conference 2011.

[14] He-Xin Xu, Guang- Ming Wang and Ke Lu, "Micro strip Rat-race Couplers”, IEEE Microwave magazine, June-2011, pp.117-129.

[15] J. Reed and C.J. Wheeler, "Method of Analysis of Symmetrical Four- Port Networks", IRE trans. On Microwave Theory and Techniques, Vol. MTT-4, pp. 246-252, October 1956.

[16] Spectrum, Elektrotechnik GmbH, "quick Connections, the 99 hand book” 80905, Munich Germany. 